Acta Crystallographica Section A

Foundations of Crystallography

ISSN 0108-7673

Received 30 May 2007

Accepted 6 August 2007

C 2008 International Union of Crystallography Printed in Singapore - all rights reserved

\section{Fascinating quasicrystals}

\author{
Walter Steurer* and Sofia Deloudi
}

Laboratory of Crystallography, Department of Materials, ETH Zurich, Wolfgang-Pauli-Strasse 10,
$\mathrm{CH}-8093$ Zurich, Switzerland. Correspondence e-mail: steurer@mat.ethz.ch

It took Dan Shechtman more than two years to get his discovery of an Al-Mn phase with icosahedral diffraction symmetry and sharp Bragg reflections published. A paradigm shift had to take place before this novel ordering state of matter - seemingly contradicting crystallographic laws - could be accepted. Today, more than 25 years later, the existence of quasicrystals is beyond doubt. However, not everything is settled yet. All the factors governing formation, growth, stability and structure of quasicrystals are still not fully understood, nor is it resolved whether their structures are strictly or only on average quasiperiodic, and it is still an open question why only quasicrystals with 5-, 8-, 10- and 12-fold rotational symmetry have been experimentally observed so far. These points will be addressed in this review article.

\section{Introduction}

'Go away, Dany. These are twins and that's not terribly interesting.' This was the first reaction of the eminent metallurgist John W. Cahn (NIST) when first faced with Dan Shechtman's electron diffraction patterns of rapidly quenched Al-Mn (La Brecque, 1987/8). John W. Cahn soon changed his mind and co-authored the first publication on the discovery of quasicrystals (Shechtman et al., 1984). Therein the authors explicitly state, demonstrating that they are fully familiar with the laws of crystallography, that crystals 'cannot and do not exhibit the icosahedral point group symmetry'. Other early sceptics such as double Nobel laureate Linus Pauling never accepted the reality of quasiperiodic order: 'Apparent icosahedral symmetry is due to directed multiple twinning of cubic crystals' (Pauling, 1985). However, the increasing quality of quasicrystals and their diffraction data forced him to use continuously larger unit cells for his twinning models, from a mere 1120 (Pauling, 1985) up to a remarkable 19400 atoms per unit cell (Pauling, 1989). Linus Pauling and his apologists simply refused to accept the paradigm shift in crystallography transforming three-dimensional non-crystallographic fivefold symmetry into a higher-dimensional crystallographic one. Following custom, we will say that a symmetry operation is crystallographic if it is compatible with a three-dimensional lattice and non-crystallographic otherwise.

The seeds for the understanding of quasicrystals were sown several years before Shechtman's discovery: by Roger Penrose (1974), who found the famous pentagonal tiling, which was popularized by Gardner (1977); by Alan Mackay (1982), who performed optical diffraction experiments on one of the Penrose tilings and obtained the first sharp diffraction pattern with decagonal symmetry; by Nicolaas de Bruijn (1981), who introduced the higher-dimensional approach for quasicrystals by defining vertex selection rules (occupation domains) for the
Penrose tiling. Based on these and other works, Levine \& Steinhardt (1984) presented the outline of a first theory of quasicrystals only six weeks after the publication of Dan Shechtman's historic paper.

However, if quasicrystals are not multiple twins, what are they? Before answering this question, we should agree on the definition of a crystal. Some years ago, the IUCr Ad Interim Commission on Aperiodic Crystals published a working definition (International Union of Crystallography, 1992): "by 'crystal' we mean any solid having an essentially discrete diffraction diagram, and by aperiodic crystal we mean any crystal in which three-dimensional lattice periodicity can be considered to be absent. As an extension, the latter term will also include those crystals in which three-dimensional periodicity is too weak to describe significant correlations in the atomic configuration, but which can be properly described by crystallographic methods developed for actual aperiodic crystals." In other words, the previous key feature of a crystal, its three-dimensional lattice periodicity, was abandoned by this definition. Instead, a pure point Fourier spectrum (reciprocalspace image) was postulated as the necessary and sufficient condition. Consequently, if the experimentally observed quasicrystals are single-phase and single-domain materials, they are aperiodic crystals. Recently, the discussion on the crystal definition has been resumed because the term 'essentially discrete diffraction diagram' was found too vague for a definition (see Steurer, 2007a; Lifshitz, 2007; Ben Abraham, 2007; Baake \& Frettlöh, 2007; Senechal, 2007; Janssen, 2007; Zimmermann, 2007). For an in-depth introduction into the field of aperiodic crystals, see Janssen et al. (2007).

The wrong assumption that the icosahedral diffraction symmetry of quasicrystals must be the result of multiple twinning was based on two premises. The first was that sharp Bragg reflections are the necessary and sufficient sign of lattice 
symmetry. The second was that a lattice cannot be invariant under the icosahedral point group. The weak point in this argument is the second premise, which is not generally true. Almost 60 years ago, Carl Hermann demonstrated that symmetry operations, which are non-crystallographic for three-dimensional lattices, can become crystallographic in the case of higher-dimensional lattices (Hermann, 1949). A sixdimensional hypercubic lattice is invariant under the icosahedral point group and so is its three-dimensional image which results from proper projection. It is therefore obvious to check whether the three-dimensional diffraction pattern of a quasicrystal can be considered as a projection of a hypothetical sixdimensional one. Indeed, this is possible. According to Fourier theory, a projection in Fourier (reciprocal) space corresponds to a section in structure (direct) space. Consequently, the structure of a quasicrystal can be interpreted as a threedimensional cut of a hypothetical six-dimensional hypercrystal structure. This is nothing else but the higher-dimensional approach, originally introduced for the description of incommensurately modulated structures (de Wolff, 1974) and later adapted for quasiperiodic structures (de Bruijn, 1981; Janssen, 1986, and references therein). The higher-dimensional approach is illustrated in Fig. 1 on a one-dimensional example, the quasiperiodic Fibonacci sequence.

Thus, quasicrystals are a subclass of the aperiodic crystals with quasiperiodic structures. The term quasiperiodic was first defined for special cases of almost periodic functions by Harald Bohr (1925). A function is quasiperiodic if its Fourier transform is only different from zero on a Fourier module of finite rank (Axel \& Gratias, 1995, and references therein). Quasiperiodic structures can be divided into two main classes: those with crystallographic point-group symmetry, to which the long-known incommensurately modulated structures and composite structures belong, and those with non-crystallographic point-group symmetry, to which quasicrystal structures belong. Their common feature is that their diffraction patterns, $M^{*}=\left\{I(\mathbf{H}) \mid \mathbf{H}=\sum h_{i} \mathbf{a}_{i}^{*}, i=1, \ldots, n, h_{i} \in \mathbb{Z}\right\}$, can be indexed based on a set of $n$ reciprocal basis vectors $\mathbf{a}_{i}^{*}$, with $n>d, d$ being the dimension of physical space (usually $d=3$ ). In other words, the Fourier module corresponds to a $\mathbb{Z}$ module of rank $n$ in a space of dimension $d<n$. In the case of periodic structures, $d=n$. To some extent, quasicrystal structures can be described as incommensurately modulated structures (Steurer, 2000a). This works well for one-dimensional quasicrystal structures as the Fibonacci sequence. However, since this description is based on the existence of a periodic average structure with one-to-one mapping of the vertices of the quasiperiodic structure and lattice nodes of the periodic average structure (Steurer \& Haibach, 1999; Cervellino \& Steurer, 2002, and references therein), it is less adequate in the case of quasiperiodic structures. The absence of one-to-one mapping for structures with non-crystallographic symmetry results from the fact that the point-group symmetry of the periodic average structure is lower than that of the quasicrystal structure. Vice versa, it can be adequate to describe an incommensurately modulated structure as a quasicrystal structure if it shows scaling symmetry or results from a phase transformation of a quasicrystal (Steurer, 2005).

In the following, we will use the terms quasicrystal and quasicrystal structure for the class of aperiodic crystals and quasiperiodic structures with non-crystallographic pointgroup symmetry. This takes into account that the term quasicrystal was coined by Levine \& Steinhardt (1984) to distinguish the newly discovered icosahedral Al-Mn phase (Shechtman et al., 1984) from the long-known incommensurately modulated structures.

\section{Occurrence of quasicrystals}

Quasicrystals have hitherto been found in more than a hundred binary and ternary intermetallic systems. About half of them are metastable and can only be obtained by rapid

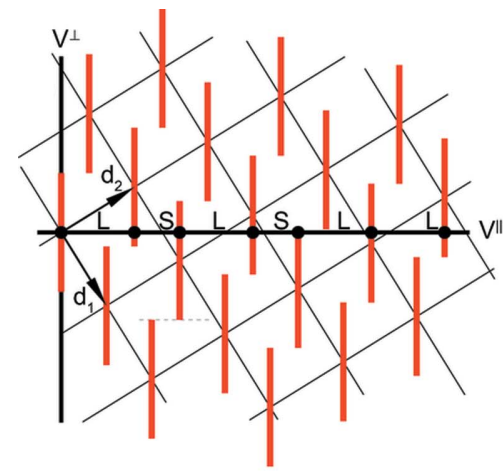

(a)

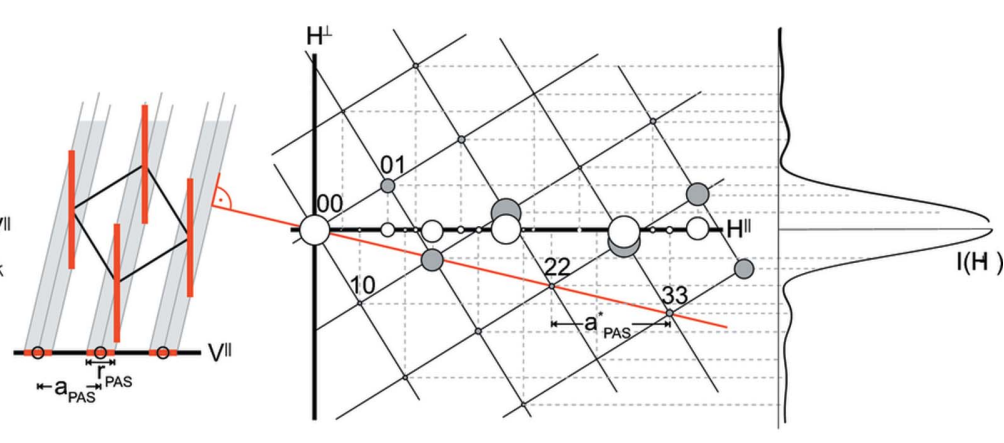

(c)

Figure 1

The one-dimensional Fibonacci sequence in the two-dimensional description. (a) The quasiperiodic sequence ... LSLSLL ... [L (S) means long (short) interval] results from the cut of the two-dimensional hypercrystal structure by the physical space, $V^{\|}$. The two-dimensional lattice is decorated with line segments (atomic surfaces or occupation domains) parallel to the perpendicular space, $V^{\perp}$. (b) A one-dimensional periodic average structure can be obtained by oblique projection of the two-dimensional structure along the grey stripes. (c) The one-dimensional diffraction pattern results from the projection of the two-dimensional one onto physical space. The intensities, $I\left(H^{\perp}\right)$, of the Bragg reflections decrease with the function (sin $\left.H^{\perp} / H^{\perp}\right)^{2}$ drawn on the right. The reflections related to the periodic average structure are connected by the red line perpendicular to the projection direction in $(b)$. 
Table 1

Quantitative X-ray structure analyses of decagonal quasicrystals.

\begin{tabular}{lrrllll}
\hline Nominal composition & $N_{\text {ref }} \dagger$ & $N_{\text {par }} \dagger$ & $R \dagger$ & $w R \dagger$ & Year & Reference \\
\hline $\mathrm{Al}_{65} \mathrm{Co}_{15} \mathrm{Cu}_{20}$ & 259 & 11 & 0.167 & 0.098 & 1990 & Steurer \& Kuo (1990) \\
$\mathrm{Al}_{70} \mathrm{Co}_{20} \mathrm{Ni}_{10}$ & 41 & 2 & 0.110 & - & 1990 & Yamamoto et al. $(1990)$ \\
$\mathrm{Al}_{70} \mathrm{Co}_{15} \mathrm{Ni}_{15}$ & 253 & 21 & 0.091 & 0.078 & 1993 & Steurer et al. $(1993)$ \\
$\mathrm{Al}_{70} \mathrm{Co}_{15} \mathrm{Ni}_{15}$ & 253 & 18 & 0.092 & 0.080 & 1995 & Elcoro \& Perez-Mato (1995) \\
$\mathrm{Al}_{72} \mathrm{Co}_{8} \mathrm{Ni}_{20}$ & 449 & 103 & 0.063 & 0.045 & 2001 & Takakura, Yamamoto \& Tsai (2001) \\
$\mathrm{Al}_{70.6} \mathrm{Co}_{6.7} \mathrm{Ni}_{22.7}$ & 2767 & 750 & 0.170 & 0.060 & 2002 & Cervellino et al. $(2002)$ \\
$\mathrm{Al}_{70.6} \mathrm{Co}_{6.7} \mathrm{Ni}_{22.7}$ & 1544 & 181 & 0.103 & 0.051 & 2004 & Takakura et al. $(2004)$ \\
$\mathrm{Al}_{72} \mathrm{Co}_{8} \mathrm{Ni}_{20}$ & 1873 & 181 & 0.081 & 0.052 & 2004 & Takakura et al. $(2004)$ \\
$\mathrm{Al}_{70.6} \mathrm{Co}_{6.7} \mathrm{Ni}_{22.7}$ & 1544 & 106 & 0.159 & 0.086 & 2004 & Mihalkovic et al. $(2004)$ \\
$\mathrm{Al}_{78} \mathrm{Mn}_{22}$ & 233 & 18 & 0.305 & 0.144 & 1991 & Steurer (1991) \\
$\mathrm{Al}_{70.5} \mathrm{Mn}_{16.5} \mathrm{Pd}_{13}$ & 476 & 33 & 0.249 & 0.214 & 1994 & Steurer et al. (1994) \\
$\mathrm{Al}_{70} \mathrm{Mn}_{17} \mathrm{Pd}_{13}$ & 1311 & 72 & 0.270 & 0.186 & 1995 & Yamamoto et al. $(1995)$ \\
$\mathrm{Al}_{70.5} \mathrm{Mn}_{16.5} \mathrm{Pd}_{13}$ & 476 & 97 & 0.084 & 0.067 & 1997 & Mihalkovic \& Mrafko $(1997)$ \\
$\mathrm{Al}_{70} \mathrm{Mn}_{17} \mathrm{Pd}_{13}$ & 1428 & 121 & 0.234 & 0.129 & 1997 & Weber \& Yamamoto (1997) \\
$\mathrm{Al}_{70} \mathrm{Mn}_{17} \mathrm{Pd}_{13}$ & 1428 & 217 & 0.167 & 0.119 & 1998 & Weber \& Yamamoto (1998) \\
$\mathrm{Al}_{75} \mathrm{Os}_{10} \mathrm{Pd}_{15}$ & 1738 & 14 & - & 0.140 & 2002 & Cervellino et al. (2002) \\
\hline
\end{tabular}

$\dagger N_{\text {ref: }}$ : number of reflections; $N_{\text {par: }}$ number of refined parameters; $(w) R$ : (weighted) reliability factor. all quasiperiodic tilings with $N$-fold symmetry, where $N$ is any integer not divisible by four. Weak matching rules are local rules ensuring uniformly bound fluctuations in perpendicular space. Consequently, given proper local interactions, quasicrystals with symmetries other than 5-, 8, 10and 12 -fold may be possible.

The predominance of IQCs is not surprising because the icosahedral coordination is the most frequent type of atomic environment in complex intermetallic phases (Daams \& Villars, 2000) and because quasiperiodic order apparently allows the best packing of clusters with icosahedral symmetry. While there are no solidification techniques (such as splat cooling or melt spinning). According to their diffraction symmetry, one distinguishes between $N$-gonal (octagonal, decagonal, dodecagonal) and icosahedral quasicrystals. More than 20 stable decagonal quasicrystals (DQCs) and more than 50 stable icosahedral quasicrystals (IQCs) are known. The few octagonal quasicrystals discovered so far are metastable, the dodecagonal ones are metastable or of very poor quality (for a comprehensive review, see Steurer, 2004a). Quasicrystals with other rotational symmetries have not been observed so far although, according to the projection model, $N$ could be any integer number theoretically. Why? For the hypothetical case of twodimensional structures, it has been shown that only quasicrystals based on quadratic irrationalities, $a+b \sqrt{c}(a, b, c$ rational numbers), should be energetically stable (Levitov, 1988). Accordingly, only QCs with 5-, 8-, 10- and 12-fold symmetries would be allowed. However, as demonstrated by Joshua Socolar (1990), at least weak matching rules exist for regular or semi-regular three-dimensional polyhedra with rotational symmetry higher than five, three-dimensional axial polyhedra can have any rotational symmetry. Examples for structures with such polyhedra are ternary borides and borocarbides with heptagonal-bipyramidal structure motifs (see Steurer, 2007b). Consequently, it is not unlikely that heptagonal approximants or even quasicrystals will be prepared some day. Stability regions of known DQCs and IQCs are displayed in Fig. 2. Some of them, such as decagonal ( $d-)$ Al$\mathrm{Fe}-\mathrm{Ni}$, exist only in a narrow temperature and composition window, while others, such as icosahedral (i-) $\mathrm{Cd}-\mathrm{Mg}-\mathrm{Yb}$, show large stability ranges.

Recently, a dendrimer-based liquid quasicrystal with 12-fold symmetry was discovered (Zeng et al., 2004), showing that quasiperiodicity is not restricted to intermetallic phases and does not necessarily require electronic stabilization. Additionally, the quasiperiodic phase transforms into a cubic phase upon heating, which indicates that the quasiperiodic state is

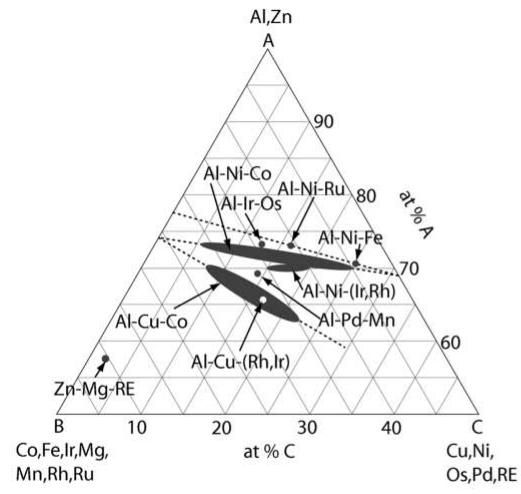

(a)

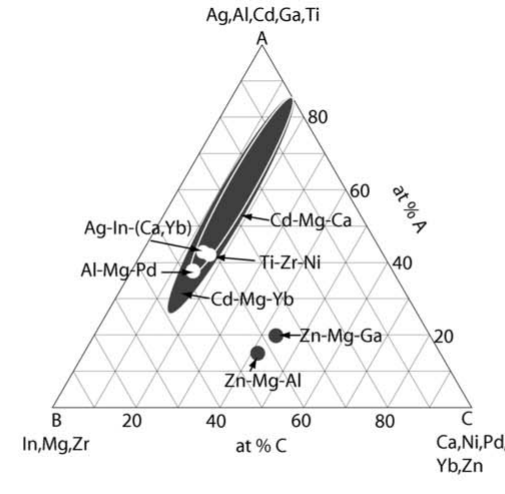

(b)

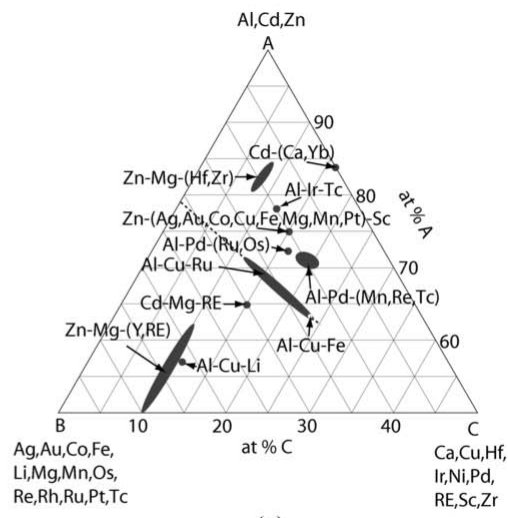

(c)

Figure 2

Stability regions of (a) DQCs and (b), (c) IQCs. RE denotes the rare-earth metals Y, Dy, Ho, Er, Tm, Lu in the case of $d-\mathrm{Zn}-\mathrm{Mg}-\mathrm{RE}$; Nd, Eu, Gd, Tb, Dy, $\mathrm{Ho}, \mathrm{Er}, \mathrm{Tm}, \mathrm{Yb}, \mathrm{Lu}$ in the case of $i$-Cd-Mg-RE; $\mathrm{La}, \mathrm{Ce}, \mathrm{Pr}, \mathrm{Nd}, \mathrm{Gd}, \mathrm{Tb}, \mathrm{Dy}, \mathrm{Ho}$, Er, $\mathrm{Yb}$ in the case of $i$-Zn-Mg-RE. Note that only the $A$-rich parts $(50 \leq A \leq 100$ at.\%) of the concentration diagrams are shown in $(a)$ and (c) (the figures are based on Grushko \& Velikanova, 2004). 
Table 2

Quantitative X-ray and neutron structure analyses of icosahedral quasicrystals.

\begin{tabular}{|c|c|c|c|c|c|c|}
\hline Nominal composition & $N_{\text {ref }} \dagger$ & $N_{\text {par }} \dagger$ & $R \dagger$ & $w R \dagger$ & Year & Reference \\
\hline $\mathrm{Al}_{73} \mathrm{Mn}_{21} \mathrm{Si}_{6}$ & 17 & 1 & 0.128 & 0.257 & 1988 & Cahn et al. (1988) \\
\hline $\mathrm{Al}_{73} \mathrm{Mn}_{21} \mathrm{Si}_{6}$ & 17 & 2 & 0.089 & - & 1994 & Mihalkovic \& Mrafko (1994) \\
\hline $\mathrm{Al}_{73} \mathrm{Mn}_{21} \mathrm{Si}_{6}$ & $32 \ddagger$ & 2 & 0.160 & - & 1994 & Mihalkovic \& Mrafko (1994) \\
\hline $\mathrm{Al}_{6} \mathrm{CuLi}_{3}$ & 37 & 6 & 0.070 & - & 1988 & Elswijk et al. (1988) \\
\hline $\mathrm{Al}_{6} \mathrm{CuLi}_{3}$ & 37 & 12 & 0.070 & 0.050 & 1991 & van Smaalen et al. (1991) \\
\hline $\mathrm{Al}_{57} \mathrm{Cu}_{11} \mathrm{Li}_{32}$ & 56 & 6 & 0.080 & 0.170 & 1991 & de Boissieu et al. (1991) \\
\hline $\mathrm{Al}_{57} \mathrm{Cu}_{11} \mathrm{Li}_{32}$ & $40 末$ & 6 & 0.080 & 0.140 & 1991 & de Boissieu et al. (1991) \\
\hline $\mathrm{Al}_{57} \mathrm{Cu}_{11} \mathrm{Li}_{32}$ & 56 & 7 & 0.076 & - & 1992 & Yamamoto (1992) \\
\hline $\mathrm{Al}_{57} \mathrm{Cu}_{11} \mathrm{Li}_{32}$ & $40 \$$ & 7 & 0.085 & - & 1992 & Yamamoto (1992) \\
\hline $\mathrm{Al}_{57} \mathrm{Cu}_{11} \mathrm{Li}_{32}$ & 56 & 19 & 0.072 & 0.067 & 1994 & Elcoro \& Perez-Mato (1994) \\
\hline $\mathrm{Al}_{57} \mathrm{Cu}_{11} \mathrm{Li}_{32}$ & $40 \ddagger$ & 19 & 0.068 & 0.068 & 1994 & Elcoro \& Perez-Mato (1994) \\
\hline $\mathrm{Al}_{63} \mathrm{Cu}_{25} \mathrm{Fe}_{12}$ & $72 \ddagger$ & - & 0.206 & - & 1991 & Cornier-Quiquandon et al. (1991) \\
\hline $\mathrm{Al}_{62} \mathrm{Cu}_{25.5} \mathrm{Fe}_{12.5}$ & 131 & - & 0.051 & 0.038 & 1995 & Katz \& Gratias (1995) \\
\hline $\mathrm{Al}_{62} \mathrm{Cu}_{25} \mathrm{Fe}_{13}$ & 935 & - & 0.11 & - & 2004 & Yamamoto, Takakura \& Tsai (2004) \\
\hline $\mathrm{Al}_{62} \mathrm{Cu}_{25} \mathrm{Ru}_{13}$ & 1080 & - & 0.88 & - & 2004 & Yamamoto, Takakura \& Tsai (2004) \\
\hline $\mathrm{Al}_{68.7} \mathrm{Mn}_{9.6} \mathrm{Pd}_{21.7}$ & 360 & - & 0.110 & - & 1992 & Boudard et al. (1992) \\
\hline $\mathrm{Al}_{70} \mathrm{Mn}_{9} \mathrm{Pd}_{21}$ & $192 \ddagger$ & - & 0.200 & - & 1992 & Boudard et al. (1992) \\
\hline $\mathrm{Al}_{70} \mathrm{Mn}_{10} \mathrm{Pd}_{20}$ & 1137 & - & 0.150 & 0.260 & 1994 & Yamamoto et al. (1994) \\
\hline $\mathrm{Al}_{70} \mathrm{Mn}_{10} \mathrm{Pd}_{20}$ & 1137 & 51 & 0.200 & 0.106 & 1995 & Yamamoto et al. (1995) \\
\hline $\mathrm{Al}_{71} \mathrm{Mn}_{8} \mathrm{Pd}_{21}$ & 377 & 91 & 0.054 & 0.053 & 2002 & Yamamoto et al. (2002) \\
\hline $\mathrm{Al}_{70.5} \mathrm{Mn}_{8.5} \mathrm{Pd}_{21}$ & $200 \S$ & - & - & - & 2003 & Fang et al. (2003) \\
\hline Al-Mn-Pd & 493 & - & 0.049 & 0.055 & 2003 & Yamamoto et al. (2003) \\
\hline $\mathrm{Al}_{73} \mathrm{Re}_{9} \mathrm{Pd}_{18}$ & 1312 & - & 0.076 & 0.107 & 2004 & Yamamoto, Takakura, Ozeki et al. (2004) \\
\hline $\mathrm{Ti}_{41.5} \mathrm{Zr}_{41.5} \mathrm{Ni}_{17}$ & $15+23-$ & 9 & 0.059 & 0.051 & 2003 & Hennig et al. (2003) \\
\hline $\mathrm{Zn}_{60} \mathrm{Mg}_{31} \mathrm{Ho}_{9}$ & 326 & - & 0.160 & - & 2001 & Takakura, Shiono et al. (2001) \\
\hline $\mathrm{Cd}_{5.7} \mathrm{Yb}$ & 5024 & 251 & 0.094 & 0.056 & 2007 & Takakura et al. (2007) \\
\hline
\end{tabular}

$\dagger N_{\text {ref: }}$ : number of reflections; $N_{\text {par }}$ : number of refined parameters; $(w) R$ : (weighted) reliability factor. $\ddagger$ Neutron scattering study, otherwise X-ray diffraction analysis. $\S$ Refinement based on CBED data. $\uparrow$ Combined X-ray and neutron powder diffraction data refinement

energetically favoured at low temperature. A model explaining the particular stability of dodecagonal soft quasicrystals has been suggested by Lifshitz \& Diamant (2007). They impose two requirements for quasiperiodicity: two different natural length scales and the existence of effective three-body interactions.

\section{Where are the atoms?}

This question, which is also part of the title of a paper by Per Bak (1986), is still not fully answered in spite of the many structure analyses that have been performed during the past two decades (see Tables 1 and 2). Why is quasicrystal structure analysis that demanding, such a 'monumental job' as Per Bak foresaw it? And what exactly do we want to know about a quasicrystal structure (for a critical discussion, see Steurer, $2004 b)$ ?

\subsection{Structure analysis}

The goal of a standard structure analysis is the determination of the atomic parameters for all atoms located in the asymmetric unit, in other words, the determination of the short-range order. The long-range order, i.e. the lattice periodicity, is taken for granted. The ultimate goal of quasicrystal structure analysis is to determine both short- and longrange order. This is equivalent to determining the kind of quasiperiodic tiling (quasilattice) underlying the quasicrystal structure and the way the unit tiles (unit cells of the tiling) are decorated by atoms. While the lattice underlying a periodic structure consists of translated copies of a single unit cell, a quasilattice consists of copies of at least two different unit tiles. Furthermore, while we have to choose between only 14 different three-dimensional point lattices (Bravais lattices) in the case of periodic crystal structures, the number of different threedimensional quasiperiodic tilings (quasilattices) is infinite. The problem of determining the quasilattice cannot be generally separated from determining the quasicrystal structure. Furthermore, the atomic decoration of the tiles may not be uniform all over the tiling.

The following fundamental questions are to be answered by quasicrystal structure analysis.

(i) Is the structure of quasicrystals quasiperiodic in the strict sense with just phononic and phasonic random fluctuations? Is it still quasiperiodic at $T=0 \mathrm{~K}$, i.e. does a quasiperiodic ground state of matter exist? Are there a finite number of well defined clusters decorating a quasilattice, which force quasiperiodicity via overlap rules, perhaps assisted by a kind of Hume-Rothery mechanism?

(ii) Does, alternatively, the random-tiling model apply (Gähler \& Jeong, 1995; Joseph \& Baake, 1996; Elser, 1996; Nienhuis, 1998; Ebinger et al., 1998; Gummelt, 2006; Henley, 2006)? A random tiling is probable in the case that the structure formation is governed by short-range atomic interactions only. In this case, the ground state would be periodic.

All quantitative structure analyses performed so far have been based on the presumption that the sharp reflections observed by diffraction methods are Bragg reflections. This implies that the strict random-tiling model (Tang, 1990; Strandburg, 1991; Henley et al., 2000) is ruled out. A few structure determinations have been performed on threedimensional tiling models, whereas most structure analyses employed the higher-dimensional approach. The important fundamental question on the degree of order/disorder was rarely studied experimentally. When diffuse scattering was investigated, it was usually done only beneath and in the direct surrounding of Bragg reflections (e.g. de Boissieu \& Francoual, 2005; de Boissieu et al., 2005) to get a measure for phasonic disorder, but rarely between Bragg reflections for other kinds of disorder (Kobas et al., 2005a,b).

Unfortunately, the most powerful methods developed and used for the solution of periodic structures in the last 50 years, i.e. statistical direct methods, cannot be applied directly to quasicrystal structures, despite a few not very successful 
attempts (Fu et al., 1993). Higher-dimensional Patterson methods (Steurer, 1987, 1989) work quite well, especially in combination with the symmetry-minimum function and image-seeking functions (Estermann et al., 2000). Maximumentropy methods may be used in the final stages of phase determination and particularly for the improvement of electron-density maps (Haibach et al., 2000, and references therein). Techniques that are especially efficient in higher dimensions are the local-density-elimination (LDE) method (Takakura et al., 2006; Yamamoto, Takakura, Ozeki et al., 2004; Yamamoto, Takakura \& Tsai 2004) and the chargeflipping method (Katrych et al., 2007, and references therein). The three-dimensional tiling-decoration methods rely on clusters derived from the structure of approximants. Approximants are structurally closely related to quasicrystals. In the higher-dimensional description, they result from rational cuts of the $n$-dimensional hypercrystals and are called rational approximants. Together with energy-minimization techniques, three-dimensional tiling-decoration methods lead to quite reliable results (Mihalkovic \& Mrafko, 1994, 1997; Mihalkovic \& Henley, 2004). Their direct link with physical parameters makes these results to some extent superior to those of higher-dimensional structure refinements, which may owe their low reliability factors partly to unphysical fit parameters. For a general discussion of quasicrystal structure analysis, see Steurer (2004b) and Haibach et al. (2000).

Tables 1 and 2 list all structure analyses of quasicrystals hitherto published, which can be considered quantitative for the state of the art of their time. Unfortunately, most publications do not even obey the most basic rules regarding the documentation of crystallographic information. Frequently, essential data are missing, such as chemical composition, preparation conditions, data-collection parameters, $n$-dimensional space group, metrics, number of refined parameters, refined parameters with their standard deviations, reliability factors and their definition. A detailed statistical structurefactor analysis, $F_{\text {obs }} / F_{\text {calc }}$, has hardly ever been performed, although this would be very important due to the large fraction of weak reflections in quasicrystal data sets, as weak reflections carry the information on the deviations of the idealized structure models from real atomic surfaces. This information is crucial if one wants to get indications for the stabilizing factors (chemical/substitutional and/or displacive disorder, distortions of coordination polyhedra, random phason fluctuations, ...) from the character of structural ordering. The fact that the strict rules applied for publication of standard structure analyses, which guarantee high-quality structural data, have not been adopted and adapted for quasicrystal structure determination may have been a consequence of the only marginal involvement of experienced structural crystallographers in this challenging field.

Anyway, with increasing size and quality of diffraction data sets, the quality of refined structure models could be improved considerably. The most recent ones are approaching the quality of standard structure determinations of complex intermetallic compounds. Consequently, together with the information provided by electron-microscopic methods, we now have quite a clear picture of the average local and global order in several quasicrystals. However, much less is known about the real structure of quasicrystals, i.e. the local deviations from the average structure. The study of diffuse scattering will help to clarify this point.

Umweganregung (multiple diffraction) has been considered a serious problem for structure analysis of quasicrystals from the very beginning (Mackay \& Kramer, 1985). Theoretically, Bragg reflections of icosahedral quasicrystals densely fill the reciprocal space. Thus, in a diffraction experiment, infinitely many Bragg reflections would be excited simultaneously and kinematical theory would not apply any more. The existence of Umweganregung in quasicrystals has been experimentally demonstrated by Eisenhower \& Colella (1998). In a realistic data collection set-up, the number of reflections being close to the Ewald sphere at the same time is quite limited (Fig. 3). However, although Umweganregung may occur frequently, its influence on the structure analysis may be negligible owing to the small structure factors of the reflections involved and the usual dynamic range $\left(10^{5}-10^{8}\right)$ of a diffraction experiment. However, future high-quality data collections should be carried out with corrections for Umweganregung.

\subsection{Structure models}

DQCs can be structurally classified based on the number of atomic layers per translation period along the tenfold axis. This is only a geometrical ordering principle, as DQCs are not

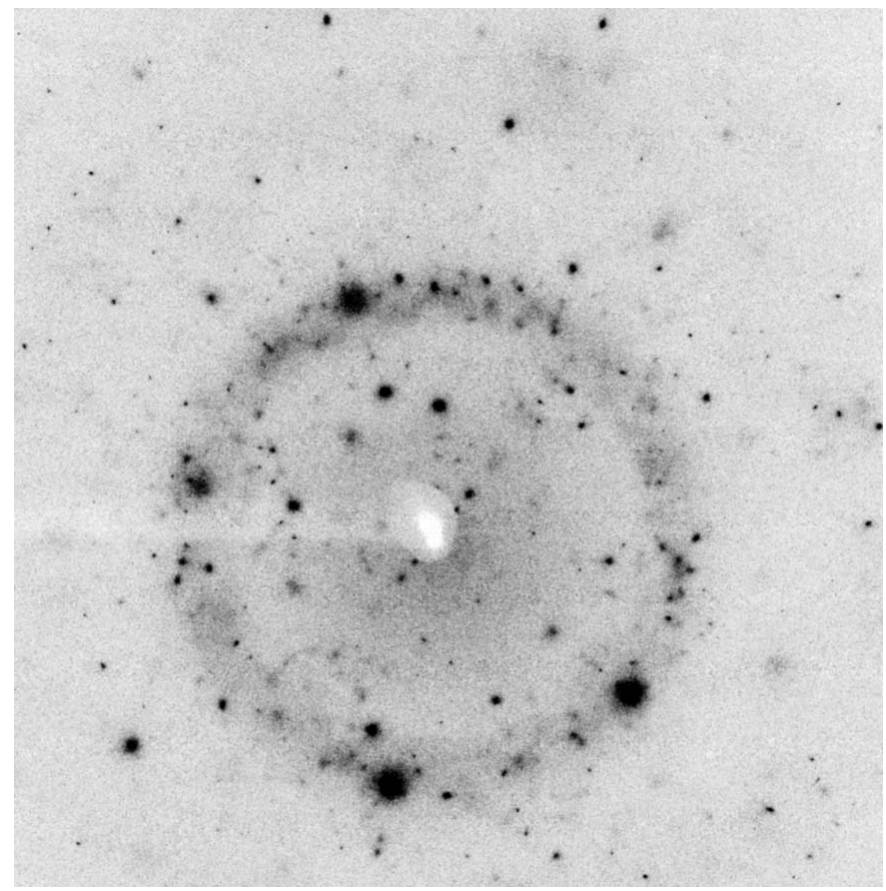

Figure 3

Typical single-frame diffraction image (oscillation angle $0.1^{\circ}$ around the horizontal axis, Pilatus $6 \mathrm{M}$ detector, $\lambda=0.76507 \AA$, fluorescence filter, crystal detector distance $300 \mathrm{~mm}$, beam divergence horizontally $0.0258^{\circ}$, vertically $0.0034^{\circ}$, exposure time $0.45 \mathrm{~s}$, SLS synchrotron radiation) of icosahedral Al-Cu-Fe (from Weber et al., 2007). A significant fraction of the reflections shown here may have been excited simultaneously leading to Umweganregung. 
layer compounds in the crystal-chemical meaning. They can be better described as packing of overlapping clusters. All stable DQCs found so far (more than 20) (see Steurer, 2004a, and references therein; Katrych et al., 2007) can be assigned to the following three classes.

(i) Two-layer periodicity (sometimes with twofold superstructure leading to a four-layer period).

$\boldsymbol{d}$-Al-Co-Ni type: $\mathrm{Al}-\mathrm{Cu}-\mathrm{Me}(\mathrm{Me}=\mathrm{Co}, \mathrm{Rh}, \mathrm{Ir}), \mathrm{Al}-\mathrm{Ni}-\mathrm{Me}$ $(\mathrm{Me}=\mathrm{Co}, \mathrm{Fe}, \mathrm{Rh}, \mathrm{Ru})$.

d-Zn-Mg-Dy type: $\mathrm{Zn}-\mathrm{Mg}-\mathrm{RE}(\mathrm{RE}=\mathrm{Y}, \mathrm{Dy}, \mathrm{Ho}, \mathrm{Er}, \mathrm{Tm}$, $\mathrm{Lu})$.

(ii) Six-layer periodicity.

$\boldsymbol{d}$-Al-Mn-Pd type: $\mathrm{Al}-\mathrm{Mn}-\mathrm{Pd}, \mathrm{Al}-\mathrm{Mn}-\mathrm{Fe}-\mathrm{Ge}, \mathrm{Ga}-\mathrm{Co}-\mathrm{Cu}$, $\mathrm{Ga}-\mathrm{Cu}-\mathrm{Fe}-\mathrm{Si}, \mathrm{Ga}-\mathrm{V}-\mathrm{Ni}-\mathrm{Si}$.

(iii) Eight-layer periodicity.

d-Al-Os-Pd type: $\mathrm{Al}-\mathrm{Ni}-\mathrm{Ru}, \mathrm{Al}-\mathrm{Pd}-\mathrm{Me}(\mathrm{Me}=\mathrm{Fe}, \mathrm{Ru}$, Os), Al-Ir-Os.

Fundamental clusters, which build the structures of quasicrystals, as well as those of their rational approximants, are often used for the classification of IQCs. There are three main types, the Mackay cluster (MC) (Mackay, 1962; Kuo, 2002) (Fig. 4), the Bergman cluster (BC) (Bergman et al., 1957) (Fig. 5) and the Tsai cluster (TC) (Palenzona, 1971; Maezawa et al., 2004) (Fig. 6).

One should keep in mind though that it is not always possible to decide unambiguously whether a quasicrystal structure is mainly built from one or other cluster type. For instance, a detailed analysis of the structure of $i$-Al-Mn-Pd demonstrated that it may be equally well covered by MCs (77.1\%) and by BCs $(72.8 \%)$, respectively (Loreto et al., 2003). A similar statistic was found for $i-\mathrm{Al}-\mathrm{Cu}-\mathrm{Fe}$ (Gratias et al., 2001). The physical nature of these clusters, their stability and mechanical properties, is still controversially discussed (see Steurer, 2006; Henley, 2006; Henley et al., 2006; Ponson et al., 2006, and references therein).

There are typical ratios, $a_{r} / \bar{d}$, of the quasilattice constant, $a_{r}$ (Elser, 1985), to the average interatomic distance, $\bar{d}$, for quasicrystals based on MCs (1.65-1.75), TCs $(\approx 1.75)$ and BCs $(\approx 2.0)$, respectively (Chen et al., 1987; Guo et al., 2002). Typical values for the optimum electron concentrations (i.e.

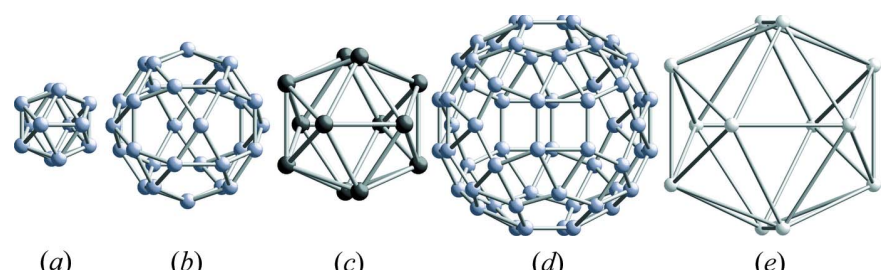

(a)

(b)

(c)

(d)

(e)

Figure 4

Shells of the double-Mackay cluster (Sugiyama et al., 1998) building the approximant $c P 138-\alpha-\mathrm{Al}-\mathrm{Mn}-\mathrm{Si}$. The shells $(a)-(e)$ are centred at the origin of the unit cell and shells $(a)-(c)$ in the body centre as well. Shells (a)-(c) form the 54 atom Mackay cluster. (a) $\mathrm{Al} / \mathrm{Si}$ icosahedron. If the icosahedral symmetry is broken by this innermost shell, the pseudoMackay cluster is obtained (Boudard et al., 1992). (b) Al icosidodecahedron. Its pentagons are capped by Mn atoms forming an icosahedron with diameter similar to the icosidodecahedron $(c)$. (d) Complex Al shell. (e) Icosahedral $\mathrm{Al} / \mathrm{Si}$ shell. valence electrons per atom) amount to $1.7-1.9$ for the MC type, 2.0-2.1 for the TC type, and 2.0-2.2 for the BC-type QCs (Trambly de Laissadière et al., 2005).

The structures of IQCs can be approximately related to cluster-decorated three-dimensional Penrose tilings with edge lengths $\tau^{3} a_{r}$ of the rhombohedra, $\tau$ being the golden mean, $\tau=2 \cos (\pi / 5)=1.618$. The quasilattice constant and the lattice parameter of the hypercubic lattice, $a$, are related by $a_{r}=a \sqrt{2} / 2$. The prototype structures and representatives, based on six-dimensional structure analyses (Yamamoto \& Takakura, 2004) and the three cluster types, respectively, are given below.

(i) $\boldsymbol{i}$-Al-Mn-Pd type: $a=9.14 \AA, a_{r}=\tau^{3} a / 2, F m \overline{3} \overline{5}$.

Three-dimensional Penrose tiling with edge length $a_{r}$ decorated by pseudo-MCs.

$\mathrm{Al}-\mathrm{Pd}-\mathrm{Me}(\mathrm{Me}=\mathrm{Mn}, \mathrm{Re}, \mathrm{Ru}, \mathrm{Os}), \mathrm{Al}-\mathrm{Cu}-\mathrm{Me}(\mathrm{Me}=\mathrm{Fe}$, $\mathrm{Ru}, \mathrm{Os})$, Ti-Zr-Ni.

(ii) $i$-Zn-Mg-Ho type: $a=10.28 \AA, a_{r}=\tau^{3} a / 2, F m \overline{3} \overline{5}$.

Three-dimensional Penrose tiling with edge length $a_{r}$ decorated by pseudo-BCs.

$\mathrm{Mg}-\mathrm{Zn}-\mathrm{RE}(\mathrm{RE}=\mathrm{Y}, \mathrm{Nd}, \mathrm{Gd}, \mathrm{Ho}, \mathrm{Dy}, \mathrm{La}, \mathrm{Pr}, \mathrm{Tb}, \mathrm{Ce})$, $\mathrm{Zn}-\mathrm{Mg}-\mathrm{Hf}, \mathrm{Zn}-\mathrm{Mg}-\mathrm{Zr}$ and $\mathrm{Al}-\mathrm{Cu}-\mathrm{Li}, \mathrm{Mg}-\mathrm{Ga}-\mathrm{Zn}, \mathrm{Mg}-\mathrm{Al}-$ $M(M=\mathrm{Rh}, \mathrm{Pd}, \mathrm{Pt})$ with symmetry $\operatorname{Pm} \overline{3} \overline{5}$ (i.e. these are disordered variants of the $F$-type).

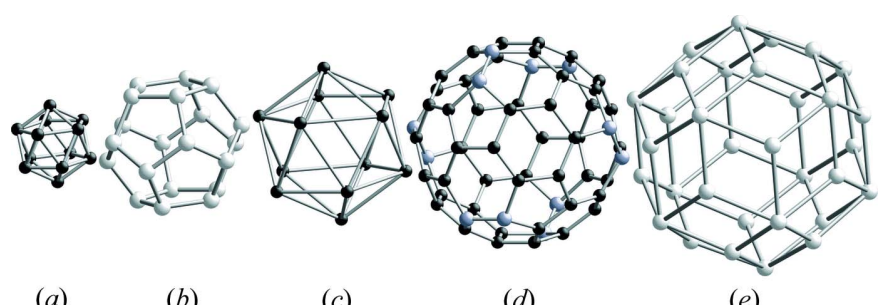

(a)

(b)

(c)

(d)

$(e)$

Figure 5

Shells of the 104 atom Samson cluster building the approximant $c I 160-R$ $\mathrm{Al}_{5} \mathrm{CuLi}_{3}$ (Audier et al., 1988). All shells are centred at the origin. Shells (a) $-(c)$ form the 44 atom Bergman cluster. (a) $\mathrm{Al} / \mathrm{Cu}$ icosahedron. (b) $\mathrm{Li}$ pentagondodecahedron. Its pentagons are capped by $\mathrm{Al} / \mathrm{Cu}$ atoms forming an icosahedron with diameter similar to the dodecahedron $(c)$. These two shells together form a triacontahedron. (d) Truncated icosahedron of $\mathrm{Al} / \mathrm{Cu}$ atoms. (e) $\mathrm{Li}$ triacontahedron with $\mathrm{Li}$ atoms capping the hexagonal faces of the truncated icosahedron.

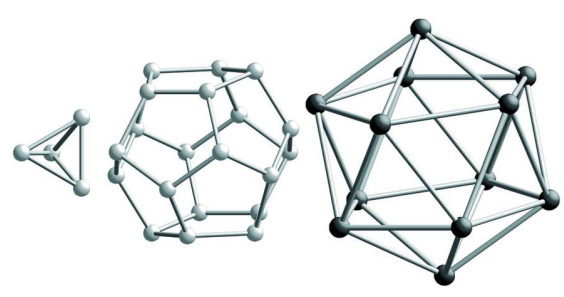

(a) (b)

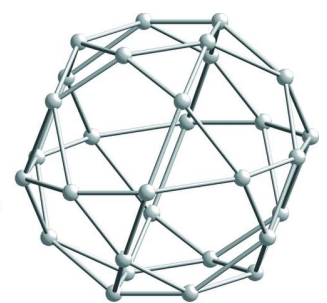

(d)
Figure 6

Shells of the 66 atom Tsai cluster building $c I 168-\mathrm{Cd}_{6} \mathrm{Yb}$ (Takakura, Shiono et al., 2001). All shells are centred at the origin. (a) Orientationally disordered $\mathrm{Cd}$ tetrahedron. (b) $\mathrm{Cd}$ pentagondodecahedron. The pentagons are capped by $\mathrm{Yb}$ forming an icosahedron $(c)$. (d) $\mathrm{Cd}$ icosidodecahedron. 
(iii) $\boldsymbol{i}$-Cd-Yb type: $a=5.689 \AA{ }^{-} a_{r}=\tau^{3} a / 2, P m \overline{3} \overline{5}$

Three-dimensional Penrose tiling with edge length $a_{r}$ decorated by TCs with disordered first shell.

$\mathrm{Cd}-\mathrm{Me}(\mathrm{Me}=\mathrm{Ca}, \mathrm{Yb}), \mathrm{Cd}-\mathrm{Mg}-\mathrm{Ca}, \mathrm{Cd}-\mathrm{Mg}-\mathrm{RE}(\mathrm{RE}=\mathrm{Y}$, $\mathrm{Nd}, \mathrm{Eu}, \mathrm{Gd}, \mathrm{Tb}, \mathrm{Dy}, \mathrm{Ho}, \mathrm{Er}, \mathrm{Tm}, \mathrm{Yb}, \mathrm{Lu}), \mathrm{Zn}-\mathrm{Me}-\mathrm{Sc}(\mathrm{Me}=$ $\mathrm{Ag}, \mathrm{Au}, \mathrm{Co}, \mathrm{Cu}, \mathrm{Fe}, \mathrm{Mg}, \mathrm{Mn}, \mathrm{Ni}, \mathrm{Pd}, \mathrm{Pt}), \mathrm{Cu}-\mathrm{Ga}-\mathrm{Mg}-\mathrm{Sc}$, $\mathrm{Zn}-\mathrm{Mg}-\mathrm{Ti}, \mathrm{Ag}-\mathrm{In}-(\mathrm{Mg}-) \mathrm{Me}(\mathrm{Me}=\mathrm{Ca}, \mathrm{Yb}) . \mathrm{Zn}$ can be

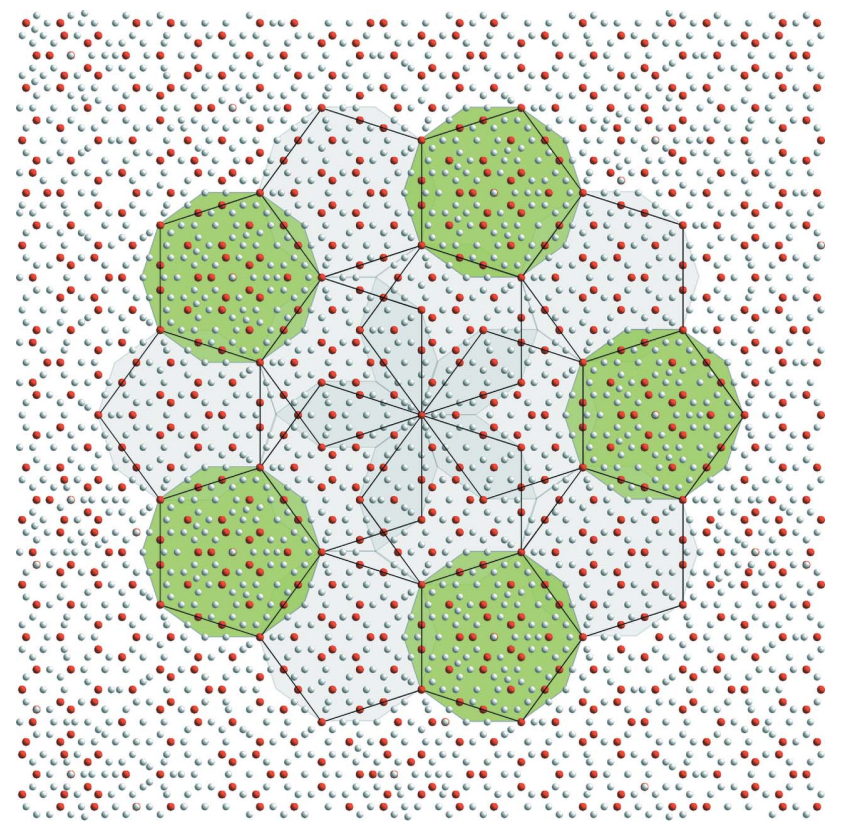

(a)

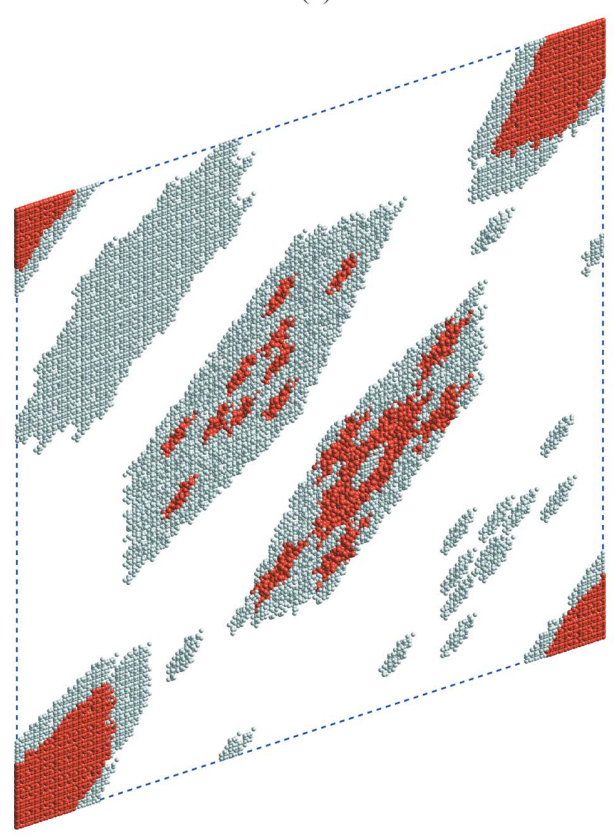

(b)

Figure 7

(a) $100 \times 100 \AA$ section of the structure of $d$-Al-Co-Ni based on a model of Deloudi \& Steurer (2007) and (b) one unit cell of its monoclinic periodic average structure, (cf. Beraha et al., 2001). Both figures show projections along the tenfold axis. The chemical decoration of the atomic surfaces is still visible after the oblique projection ( $\mathrm{Al}$ grey, $\mathrm{Co} / \mathrm{Ni}$ red). isoelectronically replaced by $\mathrm{Cu}-\mathrm{Ga}$ in the case of $i-\mathrm{Zn}-\mathrm{Mg}-$ $\mathrm{Sc}$ and $\mathrm{Cd}$ by $\mathrm{Ag}-\mathrm{In}$ in the cases of $i-\mathrm{Cd}-\mathrm{Ca}$ and $i-\mathrm{Cd}-\mathrm{Yb}$.

Two examples of idealized quasicrystal structure models, $d$-Al-Co-Ni (Deloudi \& Steurer, 2007) and $i$-Al-Cu-Fe (Quiquandon \& Gratias, 2006), together with their periodic average structures, are shown in Figs. 7 and 8. The periodic average structure can be obtained by oblique projection of the hypercrystal structure onto the physical space ( $c f$. Fig. 1). It is congruent to the infinite three-dimensional quasiperiodic structure modulo the unit cell of the periodic average structure. The periodic average structure of the decagonal phase is related to the B2 phase (CsCl-type) (Steurer, 2000b), and that of the icosahedral phase to f.c.c. Al (Steurer \& Haibach, 1999).

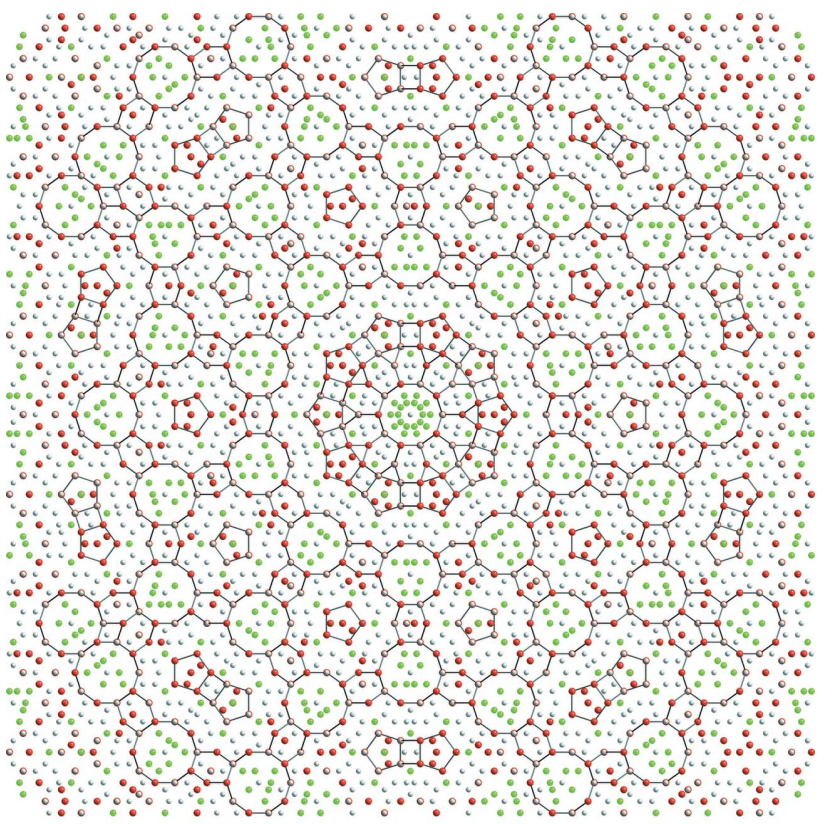

(a)

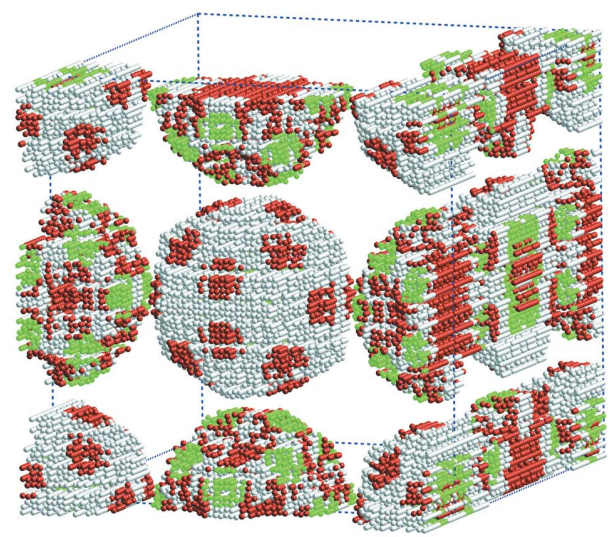

(b)

Figure 8

(a) Section of the structure of $i-\mathrm{Al}-\mathrm{Cu}-\mathrm{Fe}$ based on a model by Quiquandon \& Gratias (2006) and (b) a part (for the sake of clarity) of the unit cell of its f.c.c. periodic average structure, which is of the $\mathrm{NaCl}$ type (cf. Steurer \& Haibach, 1999). The chemical decoration of the atomic surfaces is still visible after the oblique projection ( $\mathrm{Al}$ grey, $\mathrm{Cu}$ red, $\mathrm{Fe}$ green). 
The periodic average structure is a measure for the deviation of the quasiperiodic structure from a periodic reference lattice. In the case of the one-dimensional Fibonacci sequence, a quasiperiodic structure with crystallographic symmetry, there exists a one-to-one mapping of its vertices to the reference lattice. Consequently, the deviation is purely displacive. For quasiperiodic structures with non-crystallographic symmetry, the deviation is predominantly displacive and partly substitutional (occupied/non-occupied).

Strong Bragg reflections of quasicrystals define pseudoBrillouin zones (Jones zones). Subsets of these reflections define relevant periodic average structures (Cervellino \& Steurer, 2002). This relationship has been used for the prediction of the pseudo-band-gaps of phononic quasicrystals (Sutter-Widmer et al., 2007). The Borrmann effect, i.e. anomalous transmission of X-rays, has been shown to exist in quasicrystals despite the lack of periodicity (Härtwig et al., 2001). This can be easily explained based on the concept of the periodic average structure of quasicrystals.

\section{Surfaces and interfaces}

The study of quasicrystal surfaces started in 1990 with a STM investigation of the tenfold surface of $d$-Al-Co-Cu (Kortan et al., 1990). Since then, hundreds of experimental (STM, AFM, LEED, XPS, ... ) and theoretical (molecular dynamics, Monte Carlo, ab initio calculations, ...) surface studies have been performed. These studies have contributed to our understanding of the surface structures of quasicrystals, whether they reconstruct, and how they terminate (Papadopolos \& Kasner, 2005, and references therein). Additionally, since quasicrystal surfaces usually do not reconstruct, sequences of terrace structures can also be used for checking models of the bulk structure (Papadopolos et al., 2002, and references therein).

Of particular interest have been studies of the structures adopted by atoms (Xe, $\mathrm{Na}, \mathrm{K}, \mathrm{Al}, \mathrm{Si}, \mathrm{Co}, \mathrm{Cu}, \mathrm{Sn}, \mathrm{Ag}, \mathrm{Au}, \mathrm{Pb}$, $\mathrm{Bi}, \ldots)$ or molecules $\left(\mathrm{C}_{60}\right)$ deposited on surfaces with fivefold symmetry in (sub)monolayer concentration. In almost all cases, fivefold twinned periodic domain structures are formed. However, in the case of 3-30 monolayers of Co on $d$-Al-Co$\mathrm{Ni}$ for instance, domains built by quasiperiodically spaced rows of periodically arranged atoms have been observed (Smerdon et al., 2006). For a review on all aspects of quasicrystal surface science, see the special issue edited by Pat Thiel (2004).

\section{Quasiperiodicity - origin of strange properties?}

In the first years after Shechtman's discovery, mathematicians, physicists and materials scientists jumped into quasicrystal research with both feet. Contrary to these non-crystallographers, crystallographers preferred to stay outside, perhaps because they did not feel responsible for structures with non-crystallographic symmetry. Mathematicians were particularly interested in tilings and their spectral properties. Their studies were not only important for the research in quasicrystals, they also had impact on mathematics itself in the areas of discrete geometry, harmonic analysis, group theory and ergodic theory (Lagarias, 2000), and finally promoted the understanding of ornamental art (see Lu \& Steinhardt, 2007, and references therein). Physicists and materials scientists were excited by the special properties which they envisioned to possibly result from quasiperiodicity. Since the fundamental difference between crystals and quasicrystals is in the character of their long-range order, physical properties sensitive to long-range order should be affected the most.

Indeed, particularly electronic and thermal transport properties were found to behave differently from normal metals. At low temperatures, quasicrystals even seemed to approach a metal-insulator transition (Pierce et al., 1993). This finding generated intense research in the field (for a review see Trambly de Laissadière et al., 2005). Unfortunately, it was recently shown that a significant contribution to the low conductivity of the quasicrystal with the largest effect, polycrystalline $i$-Al-Pd-Re, was of extrinsic origin (oxide layers) (Dolinšek et al., 2006). Particularly in the beginning of the hype on quasicrystals, measurements were frequently performed on low-quality and/or poorly characterized samples in order to be the first providing experimental evidence for the strange properties expected from or predicted for quasicrystals. This attitude has been responsible for many contradictory results.

However, there is still clear evidence for a significant decrease in electronic and thermal conductivity of quasicrystals with decreasing temperature. DQCs, combining both periodicity and quasiperiodicity in one and the same sample, are good model systems for separating the influence of chemical composition from that of quasiperiodicity. Indeed, there is a strong anisotropy in electronic and thermal conductivity of DQCs. For instance, measurements on $d$ - $\mathrm{Al}_{74} \mathrm{Co}_{16} \mathrm{Ni}_{10}$ between 373 and $873 \mathrm{~K}$ show a slight increase in thermal diffusivity (factor 2) in the quasiperiodic plane, while it remains constant in the periodic direction (Barrow et al., 2003). The absolute values at $373 \mathrm{~K}$ in the periodic direction are by about one order of magnitude smaller than those of pure aluminium, in the quasiperiodic plane by two orders of magnitude. The authors conclude the validity of a Drude freeelectron model in this temperature range, with a longer carrier mean-free-path time along the periodic direction. Generally, it has been shown that quasicrystals follow Wiedemann-Franz's law of the mutual relationship between thermal and electrical conductivity (Macia, 2002).

However, already small-unit-cell approximant DQCs such as $\mathrm{Al}_{13} \mathrm{Fe}_{4}\left(a=15.489, b=8.083, c=12.476 \AA, \beta=107.72^{\circ}\right)$ show a large anisotropy (factor of 5 at 4.2 and $273 \mathrm{~K}$ ) in electric resistivity as well as an inverse Matthiessen rule along the quasiperiodic plane (Volkov \& Poon, 1995). This indicates that the anisotropy in the electronic resistivity is mainly of local origin due to a highly anisotropic electronic structure (Krajci \& Hafner, 1998) and quasiperiodic long-range order is not the crucial factor. 


\section{Growth and stability of QCs}

It is generally agreed that electronic stabilization according to the Hume-Rothery mechanism plays a decisive role for Al-based quasicrystals. Indeed, many quasicrystals have been found by a systematic search for compounds with a particular valence-electron concentration for a given range of atomic size ratios and electronegativities of the elements involved (Tsai, 2003). The hybridization of low-energy empty $d$ states with a wide $s p$ band can significantly contribute to the stability as well. In the absence of a pseudogap at the Fermi energy, as observed for Cd-based quasicrystals, this mechanism may even be the dominating one (Ishii \& Fujiwara, 2001).

It is difficult to understand how a complex large-unit-cell intermetallic phase forms, even if it is periodic. How does the thousandth atom find its site in a huge unit cell? One factor is certainly the chemical composition (chemical potential), which should locally not differ too much from the global average. Another factor is the formation of structural subunits as fundamental building elements. These may just be small coordination polyhedra such as Frank-Kasper polyhedra representing the geometrically and energetically best local atomic arrangements for a given chemical composition. These may also be large clusters consisting of many shells, which are

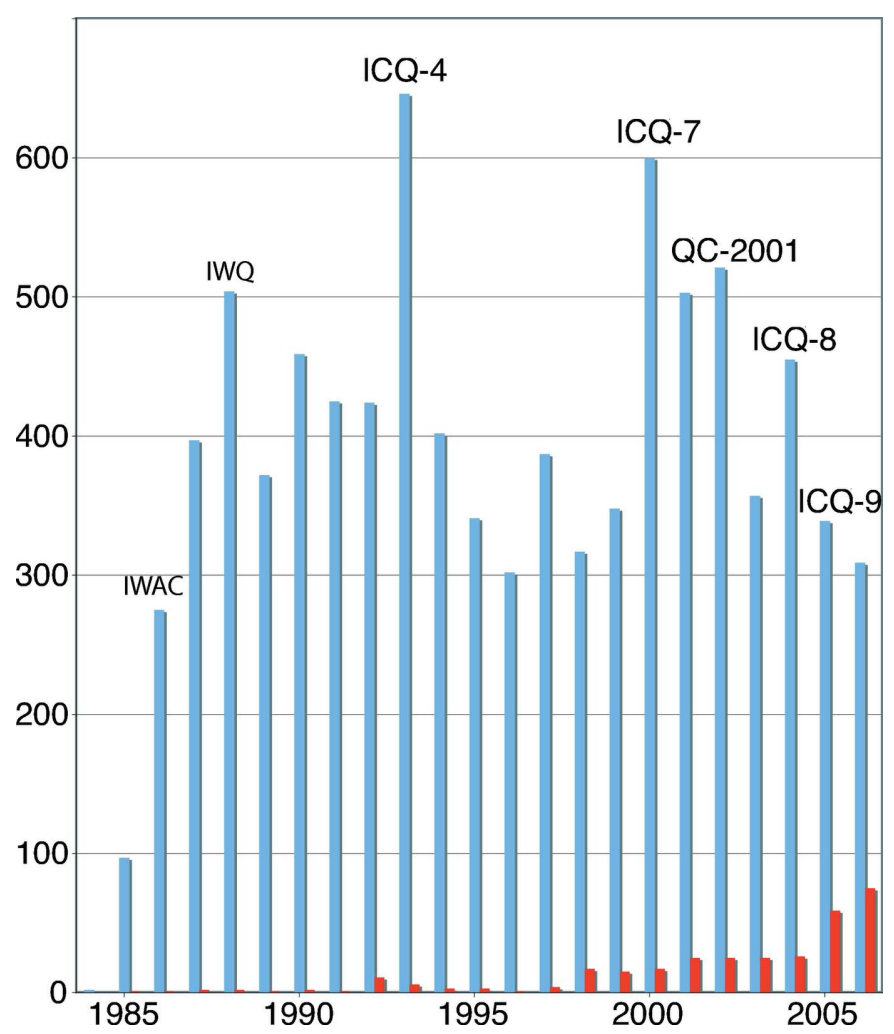

Figure 9

Number of publications related to quasicrystals (blue) and to quasiperiodic photonic and phononic crystals (red). The years with conference proceedings in ISI journals are marked (IWAC International Workshop on Aperiodic Crystals, Les Houche, France, 1986; IWQ International Workshop on Quasicrystals, Beijing, China, 1987; ICQ- $n n$th International Conference on Quasicrystals; QC-2001 Quasicrystals 2001, Sendai, Japan). probably stabilized by a particular electronic structure $[c f$. Wade's rule (Mingos, 1984, and references therein)]. The size of the unit cell is thus determined by the optimal packing of these clusters, which usually requires some glue atoms in addition. Gaps or pseudogaps in the electronic density of states at the Fermi energy can also play a role for the optimum unit-cell size. For a discussion of cluster properties in quasicrystals, see Steurer (2006), Henley (2006) and Henley et al. (2006).

It is possible that the formation of cluster-based quasicrystal structures is even simpler than that of non-cluster-based largeunit-cell complex intermetallics. It has been demonstrated by molecular dynamics that, in simple two-dimensional monoatomic models, decagonal and dodecagonal random tiling structures form if a proper double-well potential is used (Engel \& Trebin, 2007). This means that clusters, forming quasiperiodic structures, do not necessarily need to differ from their environment in terms of chemical bonding.

\section{Outlook}

Strange structures may have strange properties that may have interesting applications. This dream has been one of the main driving forces for the intense study of quasicrystals in the early years after their discovery, but it faded away. Although there is an interesting book available, Useful Quasicrystals (Dubois, 2005), quasicrystals have hitherto found only niche applications. Examples are special steels, hardened by quasicrystalline precipitates, or coatings for frying pans. Perhaps more potential for applications is shown by photonic and phononic quasicrystals (for a review, see Steurer \& Sutter-Widmer, 2007). The combination of pure point Fourier spectra with high rotational symmetry allows for wide omnidirectional band gaps even for low-index-contrast heterostructures. The number of publications in this field is rapidly growing and already represents a significant fraction of all new papers on quasicrystals (small red bars in the histogram depicted in Fig. 9).

We do not know when the next class of non-periodic exciting crystal structures will be discovered, or if there will be such a discovery at all. If nature does not have anything of this kind to offer, man-made artificial structures with complex order beyond the quasiperiodic one (Axel \& Gratias, 1995), on either the nano- or the mesoscale, may step in.

We thank the Swiss National Science Foundation for supporting part of the work discussed in this review article.

\section{References}

Audier, M., Pannetier, J., Leblanc, M., Janot, C., Lang, J. M. \& Dubost, B. (1988). Physica (Utrecht), B153, 136-142.

Axel, F. \& Gratias, D. (1995). Editors. Beyond Quasicrystals. Paris: Les Editions de Physique-Springer.

Baake, M. \& Frettlöh, D. (2007). Z. Kristallogr. 222, 312.

Bak, P. (1986). Phys. Rev. Lett. 56, 861-864.

Barrow, J. A., Cook, B. A., Canfield, P. C. \& Sordelet, D. J. (2003). Phys. Rev. B, 68, 104202. 
Ben Abraham, S. (2007). Z. Kristallogr. 222, 310.

Beraha, L., Steurer, W. \& Perez-Mato, J. M. (2001). Z. Kristallogr. 216, 573-585.

Bergman, G., Waugh, J. L. T. \& Pauling, L. (1957). Acta Cryst. 10, 254-259.

Bohr, H. (1925). Acta Math. 46, 101-214.

Boissieu, M. de \& Francoual, S. (2005). Z. Kristallogr. 220 1043-1051.

Boissieu, M. de, Francoual, S., Kaneko, Y. \& Ishimasa, T. (2005). Phys. Rev. Lett. 95, 105503.

Boissieu, M. de, Janot, C., Dubois, J. M., Audier, M. \& Dubost, B. (1991). J. Phys. Condens. Matter, 3, 1-25.

Boudard, M., de Boissieu, M., Janot, C., Heger, G., Beeli, C., Nissen, H. U., Vincent, H., Ibberson, R., Audier, M. \& Dubois, J. M. (1992). J. Phys. Condens. Matter, 4, 10149-10168.

Bruijn, N. G. de (1981). Proc. Kon. Ned. Akad. Wetenschap. A84, 39-66.

Cahn, J. W., Gratias, D. \& Mozer, B. (1988). J. Phys. Fr. 49, 1225-1233.

Cervellino, A., Haibach, T. \& Steurer, W. (2002). Acta Cryst. B58, 8-33.

Cervellino, A. \& Steurer, W. (2002). Acta Cryst. A58, 180-184.

Chen, H. S., Phillips, J. C., Villars, P., Kortan, A. R. \& Inoue, A. (1987). Phys. Rev. B, 35, 9326-9329.

Cornier-Quiquandon, M., Quivy, A., Lefebvre, S., Elkaim, E., Heger, G., Katz, A. \& Gratias, D. (1991). Phys. Rev. B, 44, 2071-2084.

Daams, J. \& Villars, P. (2000). Eng. Appl. Artif. Intell. 13, 507-511.

Deloudi, S. \& Steurer, W. (2007). Philos. Mag. 87, 2727-2732.

Dolinšek, J., McGuiness, P. J., Klanjšek, M., Smiljanić, I., Smontara, A., Zijlstra, E. S., Bose, S. K., Fisher, I. R., Kramer, M. J. \& Canfield, P. C. (2006). Phys. Rev. B, 74, 134201.

Dubois, J. M. (2005). Useful Quasicrystals. Singapore: World Scientific.

Ebinger, W., Roth, J. \& Trebin, H. R. (1998). Phys. Rev. B, 58, 8338-8346.

Eisenhower, R. \& Colella, R. (1998). Phys. Rev. B, 57, 8218-8222.

Elcoro, L. \& Perez-Mato, J. M. (1994). Acta Cryst. B50, 294-306.

Elcoro, L. \& Perez-Mato, J. M. (1995). J. Phys. I5, 729-745.

Elser, V. (1985). Phys. Rev. B, 32, 4892-4898.

Elser, V. (1996). Philos. Mag. B73, 641-656.

Elswijk, H. B., De Hosson, J. T. M., van Smaalen, S. \& de Boer, J. L. (1988). Phys. Rev. B, 38, 1681-1685.

Engel, M. \& Trebin, H. R. (2007). Phys. Rev. Lett. 98, 225505.

Estermann, M. A., Lemster, K., Haibach, T. \& Steurer, W. (2000). Z. Kristallogr. 215, 584-596.

Fang, A. H., Zou, H. M., Yu, F. M., Wang, R. H. \& Duan, X. F. (2003). J. Phys. Condens. Matter, 15, 4947-4960.

Fu, Z. Q., Li, F. H. \& Fan, H. F. (1993). Z. Kristallogr. 206, 57-68.

Gähler, F. \& Jeong, H. C. (1995). J. Phys. A28, 1807-1815.

Gardner, M. (1977). Sci. Am. 236, 110-121.

Gratias, D., Puyraimond, F., Quiquandon, M. \& Katz, A. (2001). Phys. Rev. B, 63, 024202.

Grushko, B. \& Velikanova, T. Y. (2004). J. Alloys Compd. 367, 58-63. Gummelt, P. (2006). Z. Kristallogr. 221, 582-588.

Guo, J. Q., Abe, E. \& Tsai, A. P. (2002). Philos. Mag. Lett. 82, 27-35.

Haibach, T., Cervellino, A., Estermann, M. A. \& Steurer, W. (2000). Z. Kristallogr. 215, 569-583.

Härtwig, J., Agliozzo, S., Baruchel, J., Colella, R., de Boissieu, M., Gastaldi, J., Klein, H., Mancini, L. \& Wang, J. (2001). J. Phys. D Appl. Phys. 34, A103-A108.

Henley, C. L. (2006). Philos. Mag. 86, 1123-1129.

Henley, C. L., de Boissieu, M. \& Steurer, W. (2006). Philos. Mag. 86, 1131-1151.

Henley, C. L., Elser, V. \& Mihalkovic, M. (2000). Z. Kristallogr. 215, 553-568.

Hennig, R. G., Kelton, K. F., Carlsson, A. E. \& Henley, C. L. (2003). Phys. Rev. B, 67, 134202 .

Hermann, C. (1949). Acta Cryst. 2, 139-145.

Ishii, Y. \& Fujiwara, T. (2001). Phys. Rev. Lett. 87, 206408.
International Union of Crystallography (1992). Acta Cryst. A48, 922-946.

Janssen, T. (1986). Acta Cryst. A42, 261-271.

Janssen, T. (2007). Z. Kristallogr. 222, 311.

Janssen, T., Chapuis, G. \& de Boissieu, M. (2007). Aperiodic Crystals. From Modulated Phases to Quasicrystals. IUCr Monographs on Crystallography, No. 20. IUCr/Oxford Science Publications.

Joseph, D. \& Baake, M. (1996). J. Phys. A29, 6709-6716.

Katrych, S., Weber, T., Kobas, M., Massüger, L., Palatinus, L., Chapuis, G. \& Steurer, W. (2007). J. Alloys Compd. 428, 164-172.

Katz, A. \& Gratias, D. (1995). Proceedings of ICQ5, edited by C. Janot \& R. Mosseri, p. 164. Singapore: World Scientific.

Kobas, M., Weber, T. \& Steurer, W. (2005a). Phys. Rev. B, 71, 224205.

Kobas, M., Weber, T. \& Steurer, W. (2005b). Phys. Rev. B, 71, 224206.

Kortan, A. R., Becker, R. S., Thiel, F. A. \& Chen, H. S. (1990). Phys. Rev. Lett. 64, 200-203.

Krajci, M. \& Hafner, J. (1998). Phys. Rev. B, 58, 5378-5383.

Kuo, K. H. (2002). Struct. Chem. 13, 221-230.

La Brecque, M. (1987/8). Mosaic, 18, 2-23.

Lagarias, J. C. (2000). Mater. Sci. Eng. A294, 186-191.

Levine, D. \& Steinhardt, P. J. (1984). Phys. Rev. Lett. 53, 2477-2480.

Levitov, L. S. (1988). Europhys. Lett. 6, 517-522.

Lifshitz, R. (2007). Z. Kristallogr. 222, 313-317.

Lifshitz, R. \& Diamant, H. (2007). Philos. Mag. 87, 3021-3030.

Loreto, L., Farinato, R., Catallo, S., Janot, C., Gerbasi, G. \& DeAngelis, G. (2003). Physica (Utrecht), B328, 193-203.

Lu, P. J. \& Steinhardt, P. J. (2007). Science, 315, 1016-1110.

Macia, E. (2002). Appl. Phys. Lett. 81, 88-90.

Mackay, A. L. (1962). Acta Cryst. 15, 916-918.

Mackay, A. L. (1982). Physica (Utrecht), A114, 609-613.

Mackay, A. L. \& Kramer, P. (1985). Nature (Utrecht), 316, 17-18.

Maezawa, R., Kashimoto, S. \& Ishimasa, T. (2004). Philos. Mag. Lett. 84, 215-223.

Mihalkovic, M. \& Henley, C. L. (2004). Phys. Rev. B, 70, 092202.

Mihalkovic, M., Henley, C. L. \& Widom, M. (2004). J. Non-Cryst. Solids, 334, 177-183.

Mihalkovic, M. \& Mrafko, P. (1994). Phys. Rev. B, 49, 100-108.

Mihalkovic, M. \& Mrafko, P. (1997). Mater. Sci. Eng. A226, 961-966.

Mingos, D. M. P. (1984). Acc. Chem. Res. 17, 311-319.

Nienhuis, B. (1998). Phys. Rep. 301, 271-292.

Palenzona, A. (1971). J. Less Common. Met. 25, 367-372.

Papadopolos, Z. \& Kasner, G. (2005). Phys. Rev. B, 72, 4206.

Papadopolos, Z., Kasner, G., Ledieu, J., Cox, E. J., Richardson, N. V., Chen, Q., Diehl, R. D., Lograsso, T. A., Ross, A. R. \& McGrath, R. (2002). Phys. Rev. B, 66, 184207.

Pauling, L. (1985). Nature (London), 317, 512-514.

Pauling, L. (1989). Proc. Natl Acad. Sci. USA, 86, 8595-8599.

Penrose, R. (1974). Bull. Inst. Math. Appl. 10, 266-271.

Pierce, F. S., Poon, S. J. \& Guo, Q. (1993). Science, 261, 737-739.

Ponson, L., Bonamy, D. \& Barbier, L. (2006). Phys. Rev. B, 74, 184205.

Quiquandon, M. \& Gratias, D. (2006). Phys. Rev. B, 74, 0214205.

Senechal, M. (2007). Z. Kristallogr. 222, 311.

Shechtman, D., Blech, I., Gratias, D. \& Cahn, J. W. (1984). Phys. Rev. Lett. 53, 1951-1953.

Smaalen, S. van, de Boer, J. L. \& Shen, Y. (1991). Phys. Rev. B, 43, 929-937.

Smerdon, J. A., Ledieu, J., Hoeft, J. T., Reid, D. E., Wearing, L. H., Diehl, R. D., LoGrasso, T. A., Ross, A. R. \& McGrath, R. (2006). Philos. Mag. 86, 841-847.

Socolar, J. E. S. (1990). Commun. Math. Phys. 129, 599-619.

Steurer, W. (1987). Acta Cryst. A43, 36-42.

Steurer, W. (1989). Acta Cryst. B45, 534-542.

Steurer, W. (1991). J. Phys. Condens. Matter, 3, 3397-3410.

Steurer, W. (2000a). Z. Kristallogr. 215, 323-334.

Steurer, W. (2000b). Mater. Sci. Eng. A294, 268-271.

Steurer, W. (2004a). Z. Kristallogr. 219, 391-446.

Steurer, W. (2004b). J. Non-Cryst. Solids, 334, 137-142. 
Steurer, W. (2005). Acta Cryst. A61, 28-38.

Steurer, W. (2006). Philos. Mag. 86, 1105-1113.

Steurer, W. (2007a). Z. Kristallogr. 222, 308-309.

Steurer, W. (2007b). Philos. Mag. 87, 2707-2712.

Steurer, W. \& Haibach, T. (1999). Acta Cryst. A55 48-57.

Steurer, W., Haibach, T., Zhang, B., Beeli, C. \& Nissen, H. U. (1994). J. Phys. Condens. Matter, 6, 613-632.

Steurer, W., Haibach, T., Zhang, B., Kek, S. \& Lück, R. (1993). Acta Cryst. B49, 661-675.

Steurer, W. \& Kuo, K. H. (1990). Acta Cryst. B46, 703-712.

Steurer, W. \& Sutter-Widmer, D. (2007). J. Phys. D Appl. Phys. 40, R229-R247.

Strandburg, K. J. (1991). Phys. Rev. B, 44, 4644-4646.

Sugiyama, K., Kaji, N. \& Hiraga, K. (1998). Acta Cryst. C54, 445-447.

Sutter-Widmer, D., Deloudi, S. \& Steurer, W. (2007). Phys. Rev. B, 75, 094304.

Takakura, H., Gomez, C. P., Yamamoto, A., de Boissieu, M. \& Tsai, A. P. (2007). Nature Mater. 6, 58-63.

Takakura, H., Shiono, M., Sato, T. J., Yamamoto, A. \& Tsai, A. P. (2001). Phys. Rev. Lett. 86, 236-239.

Takakura, H., Yamamoto, A., Sato, T. J., Tsai, A. P., Ozawa, Y., Yasuda, N. \& Toriumi, K. (2006). Philos. Mag. 86, 621-627.

Takakura, H., Yamamoto, A. \& Tsai, A. P. (2001). Acta Cryst. A57, 576-585.

Takakura, H., Yamamoto, A. \& Tsai, A. P. (2004). Ferroelectrics, 305, 257-260.

Tang, L. H. (1990). Phys. Rev. Lett. 64, 2390-2393.

Thiel, P. A. (2004). Prog. Surf. Sci. 75, 69-86.
Trambly de Laissadière, G., Nguyen-Manh, D. \& Mayou, D. (2005). Prog. Mater. Sci. 50, 679-788.

Tsai, A. P. (2003). Acc. Chem. Res. 36, 31-38.

Volkov, P. \& Poon, S. J. (1995). Phys. Rev. B, 52, 12685-12689.

Weber, S. \& Yamamoto, A. (1997). Philos. Mag. A76, 85-106.

Weber, S. \& Yamamoto, A. (1998). Acta Cryst. A54, 997-1005.

Weber, T., Deloudi, S., Kobas, M., Yokoyama, Y., Inoue, A. \& Steurer, W. (2007). In preparation.

Wolff, P. M. de (1974). Acta Cryst. A30, 777-785.

Yamamoto, A. (1992). Phys. Rev. B, 45, 5217-5227.

Yamamoto, A., Kato, K., Shibuya, T. \& Takeuchi, S. (1990). Phys. Rev. Lett. 65, 1603-1606.

Yamamoto, A., Matsuo, Y., Yamanoi, T., Tsai, A.P., Hiraga, K. \& Masumoto, T. (1995). Proceedings of Aperiodic'94, edited by G. Chapuis \& W. Paciorek, pp. 393-398. Singapore: World Scientific.

Yamamoto, A., Sato, A., Kato, K., Tsai, A. P. \& Masumoto, T. (1994). Mater. Sci. Forum, 150-151, 211-222.

Yamamoto, A. \& Takakura, H. (2004). Ferroelectrics, 305, 223-227.

Yamamoto, A., Takakura, H., Ozeki, T., Tsai, A. P. \& Ohashi, Y. (2004). J. Non-Cryst. Solids, 334, 151-155.

Yamamoto, A., Takakura, H. \& Tsai, A. P. (2002). J. Alloy. Compd. 342, 159-163.

Yamamoto, A., Takakura, H. \& Tsai, A. P. (2003). Phys. Rev. B, 68, 4201.

Yamamoto, A., Takakura, H. \& Tsai, A. P. (2004). Ferroelectrics, 305, 279-282.

Zeng, X. B., Ungar, G., Liu, Y. S., Percec, V., Dulcey, S. E. \& Hobbs, J. K. (2004). Nature (London), 428, 157-160.

Zimmermann, H. (2007). Z. Kristallogr. 222, 318-319. 